\title{
Acetaminophen-Cysteine Protein Adduct
}

National Cancer Institute

\section{Source}

National Cancer Institute. Acetaminophen-Cysteine Protein Adduct. NCI Thesaurus. Code C157112.

A modified protein, usually glutathione, where oxidized acetaminophen is bound to the sulfhydryl group of cysteine residues. The presence of acetaminophen-cysteine or its proteolyzed product 3-para cysteinyl acetaminophen in a sample is a specific biomarker for acetaminophen exposure and increased concentrations of these adducts may be associated with acetaminophen toxicity. 